\title{
Reforma Psiquiátrica e a Dependência Brasileira: entre o arcaico e o moderno
}

\author{
Daniel Figueiredo de Almeida Alves ${ }^{1}$ \\ https://orcid.org/0000-0003-0080-1919
}

Oziris Simões ${ }^{2}$

https://orcid.org/0000-0002-1608-0469

\author{
Leonardo Carnut ${ }^{3}$ \\ https://orcid.org/0000-0001-6415-6977
}

Áquilas Mendes ${ }^{4}$

https://orcid.org/0000-0002-5632-4333

${ }^{1}$ Faculdade de Ciências Médicas da Santa Casa de São Paulo, Curso de Medicina, São Paulo, SP, Brasil

${ }^{2}$ Faculdade de Ciências Médicas da Santa Casa de São Paulo, Departamento de Saúde Coletiva, São Paulo, SP, Brasil ${ }^{3}$ Universidade Federal de São Paulo, Centro de Desenvolvimento de Ensino Superior em Saúde, São Paulo, SP, Brasil ${ }^{4}$ Universidade de São Paulo, Faculdade de Saúde Pública, São Paulo, SP, Brasil

\section{Reforma psiquiátrica e a dependência brasileira: entre o arcaico e o moderno}

Resumo: No presente estudo, foram realizadas algumas aproximações da Política de Saúde Mental, como pressuposto da Reforma Psiquiátrica Brasileira (RPB), à luz da Teoria Marxista da Dependência (TMD), com o objetivo de analisar as implicações assistenciais e epidemiológicas desse movimento atrelado à totalidade do processo de acumulação capitalista. Com este intuito, foi abordado do ponto de vista histórico-descritivo os dados de saúde mental na cidade de São Paulo entre 2008 e 2017, promovendo uma análise qualitativa por meio do materialismo histórico-dialético. Demonstrou-se que a RPB é incompleta e hibridiza com diferentes perspectivas de saúde, o que foi constatado pela permanência de características asilares (o arcaico) em conjunto com serviços de caráter substitutivo (o moderno). Dessa maneira, explicita-se a contradição entre dependência e a constituição de uma política social em uma das principais cidades da periferia da economia mundial.

Palavras-chave: Reforma Psiquiátrica Brasileira. Saúde Mental. Saúde Coletiva. Capitalismo Dependente.

\section{Psychiatric reform and Brazilian dependence: between the archaic and the modern}

Abstract: This study carried out analysis of the Mental Health Policy, as part of the Brazilian Psychiatric Reform (BPR), based on the Marxist Dependence Theory (MDT). The objective is to understand the implications of BPR - related to the totality of the capitalist accumulation process - regarding services and epidemiology. A historical-descriptive perspective was adopted to approach the data on mental health in the city of São Paulo between 2008 and 2017, promoting a qualitative analysis through historical and dialectical materialism. The analysis demonstrates that the BPR is incomplete and hybridizes with different perspectives on health, which was verified by the permanence of asylum characteristics (the archaic) together with substitutive services (the modern). The study explains the contradiction between dependence and the constitution of social policy in a large city of a developing country.

Keywords: Brazilian Psychiatric Reform. Mental health. Collective health. Dependent capitalism.

Recebido em 30.06.2019. Aprovado em 17.09.2019. Revisado em 01.10.2009.

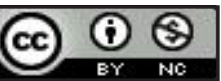

(C) O(s) Autor(es). 2020 Acesso Aberto Esta obra está licenciada sob os termos da Licença Creative Commons Atribuição-NãoComercial 4.0 Internacional (https://creativecommons.org/licenses/by-nc/4.0/deed.pt_BR), que permite copiar, distribuir e reproduzir em qualquer meio, bem como adaptar, transformar e criar a partir deste material, desde que para fins não comerciais e que você forneça o devido crédito aos autores e a fonte, insira um link para a Licença Creative Commons e indique se mudanças foram feitas. 


\section{Introdução}

Após o regime militar instaurado em 1964 e com o lento processo de redemocratização no Brasil, as diversas lutas sociais exigiam reformas setoriais. Neste contexto, a questão social tomou centralidade nos debates, inclusive na oportunidade política de formulação da Constituição 'cidadã' de 1988 (BEHRING; BOSCHETTI, 2011). Por isso, não é de se estranhar que, no bojo desta problemática, o Movimento da Reforma Sanitária Brasileira (MRSB) tentou alçar a saúde para outro nível de compreensão, pautando-a na constituinte (PAIM, 2008) e reinserindo-a na luta da classe trabalhadora.

Em que pese à relevância desta conquista, muitos analistas consideram esse processo 'reformista' ao MRSB (DANTAS, 2017; JACOBINA, 2016) - proveniente das esquerdas progressistas -, ou seja, um entrave para o seu desenvolvimento em termos radicais e com a inserção no conjunto das lutas da classe trabalhadora. Mesmo sob esta crítica, a Reforma Sanitária desdobrou-se em diversas 'reformas' subsetoriais, que, partilhavam como finalidade o horizonte da institucionalidade e seus limites. A Reforma Psiquiátrica Brasileira (RPB) certamente foi uma delas. Suas ações tenderam a se descolar da totalidade social latino-americana e mundial, desconsiderando a compreensão da dinâmica da dependência e minorando as múltiplas determinações da dinâmica social capitalista na qual a RPB está inserida.

Ao enfatizar o 'descolamento' do Brasil de sua posição de dependência em relação aos países de capitalismo central, a RPB incorreu em um problema de análise e de ação tático-estratégica. Apesar da diversidade teórica que explicam essa dinâmica, capturar o fenômeno capitalista da 'relação centroperiferia' requer uma escolha analítica que reintroduza o debate da RPB na crítica marxista. Neste intuito, optou-se pela categoria 'dependente' derivada da teoria marxista da dependência ${ }^{2}$ (MARINI, 2011; LUCE, 2018).

Em linhas gerais, a questão da dependência não pode ser explicada somente pela posição de colônia no processo sócio-histórico de formação brasileira. Mesmo este período revelando importantes determinações, o centro da análise recai na debilidade e fragilidade da conformação social da 'classe dominante', que, em sua essência, não tem a predisposição revolucionária para romper com os estigmas de colônia e engendrar um processo tipicamente capitalista (MARINI, 2011).

Assim, ao menor sinal de revolta dos de baixo, essa classe dominante volta-se para as nações colonizadoras e realiza conchavos para manutenção dos seus interesses e privilégios. Para isso, realiza reformas 'pelo alto' para perpetuar seu domínio, com intuito de modernizar ao mesmo tempo em que conserva (IANNI, 1992; FERNANDES, 2009). Esta tendência engendra uma dinâmica social particular, que, apesar da incorporação de modernas relações de produção industrial, não elimina as relações praticamente escravocratas e não assalariadas no campo. A este moderno processo de industrialização, arcaicas relações sociais são essenciais para o fortalecimento dos países imperialistas (OLIVEIRA, 2013).

Decorrente desta contradição essencial, não é possível tecer uma clara correlação entre avanço das forças produtivas de cunho capitalista e a melhoria das condições de vida da classe trabalhadora. Como descreve Oliveira, por exemplo, na obra 'Crítica à Razão Dualista' no período de maior expansão industrial - compreendido nos planos desenvolvimentistas de Juscelino Kubitschek - houve uma diminuição do salário real dos trabalhadores urbanos brasileiros (OLIVEIRA, 2013).

É nesta dinâmica da dependência que há a gênese e conformação das políticas sociais brasileiras no período pós 1988. Assim, problematizamos o lugar em que o processo da Reforma Psiquiátrica Brasileira ocupou neste contexto. Ao passo em que a centralidade da questão social estava em pauta e a redemocratização ocorria, internacionalmente havia a cristalização da hegemonia do neoliberalismo (BEHRING; BOSCHETTI, 2011). Isto incutiu no plano político das políticas sociais uma contrarreforma administrativa do Estado e por consequência o desmonte dos sistemas nacionais de proteção social.

Assim se deu a conformação do nosso sistema de proteção social, ou seja, em um profundo descompasso histórico (BEHRING; BOSCHETTI, 2011) com o movimento de acumulação capitalista. Mesmo este cenário impondo severas barreiras para o alcance do direito à saúde mental na plena concretude na vida dos brasileiros, a estruturação de seus serviços seguiu seu curso. Na tentativa de implantar as ideias da RPB, tentou-se articular diversas políticas intra e intersetoriais para formatar um sistema de proteção social possível à luz do que poderia ser um forçoso "Estado de Bem-Estar Social".

Neste bojo, a conformação das forças políticas permitiu avanços significativos em certos setores, como no caso da saúde (PAIM, 2008) e, incluindo a saúde mental. Esta força política foi materializada no Movimento da Reforma Sanitária Brasileira, cujos pressupostos podem ser resumidos na hipótese elaborada por Fleury, como um processo de transformação da norma legal e do aparelho institucional que regulamenta e se responsabiliza pela proteção à saúde dos cidadãos (FLEURY, 1989). Setorialmente, é nesse cenário em que a RPB viu a oportunidade de materializar suas ideias. 
No caminho dessa elaboração teórico-prática e no seio deste movimento político setorial, faz-nos mais sentido dizer que o Sistema Único de Saúde (SUS) foi estruturado sob os auspícios do que poderia ser um Estado Social (BOSCHETTI, 2016) ${ }^{3}$. Neste mesmo período, institucionalmente a reforma psiquiátrica tomou corpo em torno desse mote e materializou-se na Lei n $\mathrm{n}^{\circ} 10.216$ (BRASIL, 2001) que propunha alterar o modelo assistencial em Saúde Mental, discorrendo sobre a proteção e direito de portadores de transtornos mentais. Porém, a reforma não especificou novos modelos de atenção, mas apenas a necessidade de desinstitucionalização de pacientes em internações psiquiátricas de longa duração.

Neste decurso, a luta antimanicomial (AMARANTE; TORRE, 2010; TOMAZ, 2009) 4 pressionou para a implantação da Política Nacional de Saúde Mental, em 2003. Com a necessidade de implementar esta rede, nas duas décadas de 1990 a 2010 foram marcadas por uma forte expansão dos equipamentos de saúde mental, o que inclui: Centro de Atenção Psicossocial (CAPS), Serviços de Residência Terapêutica (SRT), Centros de Convivência e Cooperativa (CECCO), Centro de Atenção Integrada à Saúde Mental (CAISM), leitos em hospitais gerais e ações na atenção básica. Porém, o equipamento mais marcante e de mais forte expansão foram os CAPS com um incremento anual de $25 \%$, o que demonstra o poder indutivo das diversas portarias sobre os municípios em ambiente federativo (COSTA et al., 2011; BALLARIN; MIRANDA; FUENTES, 2010).

Este papel estratégico dos CAPS, na rede de atenção psicossocial ficou evidente pelo objetivo eminentemente substitutivo ao hospital psiquiátrico e à atribuição do direcionamento local de políticas e programas de saúde. Além disso, o CAPS considera o encaminhamento e acompanhamento dos usuários dos Serviços de Residência Terapêutica (SRT) e do apoio às equipes de Saúde da Família. Ainda, foram organizados e classificados de acordo com a abrangência da população atendida e horário de funcionamento (I, II, III, álcool/ drogas e infantil) e devem estar articulados a outras redes de serviços de saúde com intuito de compor uma resposta à complexa demanda de inclusão (BALLARIN et al., 2011).

Contudo, partimos da hipótese de que, em um país cuja inserção social capitalista dependente, apresentam-se dificuldades de implementação de suas políticas sociais devido a capacidade financeira limitada em função do comprometimento dos fundos públicos com a dinâmica mundializada entre impériodependência. No caso deste estudo, demonstraremos como essa relação se manifesta na concretude histórica da consolidação da Política Nacional de Saúde Mental e na incompletude das pautas originais da Reforma Psiquiátrica Brasileira, especialmente no que tange à organização dos serviços de caráter substitutivos e o perfil de morbimortalidade.

Partimos do pressuposto que, a contradição da dependência materializada na relação entre o moderno-arcaico também se expressa, na saúde, e aqui, especificamente, nos serviços de assistência à saúde mental. A implantação dos serviços de caráter substitutivo (o moderno) não levou ao desaparecimento da lógica asilar (o arcaico), pelo contrário, pari passu houve a implementação da ideia da Reforma Psiquiátrica Brasileira e seus serviços de lógica psicossocial, com a permanência de características manicomiais em termos de leitos e emergências.

Logo, o objetivo deste estudo é analisar os desdobramentos da política de saúde mental, oriunda dos pressupostos da Reforma Psiquiátrica na cidade de São Paulo no período entre 2008 e 2017. Dessa maneira, analisamos os dados assistenciais e epidemiológicos atrelados à totalidade do processo de acumulação capitalista, aproximando-os à compreensão da teoria marxista da dependência no contexto social brasileiro.

\section{Método}

Com o objetivo de analisar os desdobramentos da política de saúde mental, abordou-se, do ponto de vista histórico-descritivo, os dados de saúde mental na cidade de São Paulo entre 2008 e 2017, analisando-os qualitativamente. $O$ intuito foi compreender a conformação das diversas modalidades de serviços ofertados na Rede de Atenção Psicossocial sob análise do materialismo histórico-dialético. Coletou-se dados sobre evolução dos seus leitos, suas internações por causas específicas e o padrão de mortalidade por suicídio no município de São Paulo.

O conjunto destes dados pode ser considerado como dados empíricos da cidade de São Paulo, que representam uma parcela da realidade sobre a condução da Reforma Psiquiátrica no Brasil em termos de sua ideia original. Este território foi escolhido devido às suas proporções demográficas e possibilidade de implantação por ser a principal região de relativa riqueza econômica do País. Por meio desta primeira análise de tendência histórica dos dados empíricos, foram elaboradas algumas hipóteses sobre as possíveis relações de determinação entre os dados e a totalidade social estruturada pela contradição moderno-arcaico típica da formação social capitalista dependente. 


\section{Resultados}

No que tange à ampliação dos serviços de saúde mental ofertados na Rede de Atenção Psicossocial (RAPS) e nas especificidades dos CAPS, as Figuras 1 e 2 mostram uma tendência histórica. Dentre todos os serviços da RAPS, os CAPS acompanham a tendência de crescimento, além disso, o principal estágio de expansão compreende a primeira metade - período de 2008 a 2012 - da série histórica.

Figura 1 - Quantidade total de Serviços de Atenção Psicossocial (SAPS) disponibilizados na Rede de Atenção Psicossocial (RAPS,) no município de São Paulo, no período de 2008 a 2017

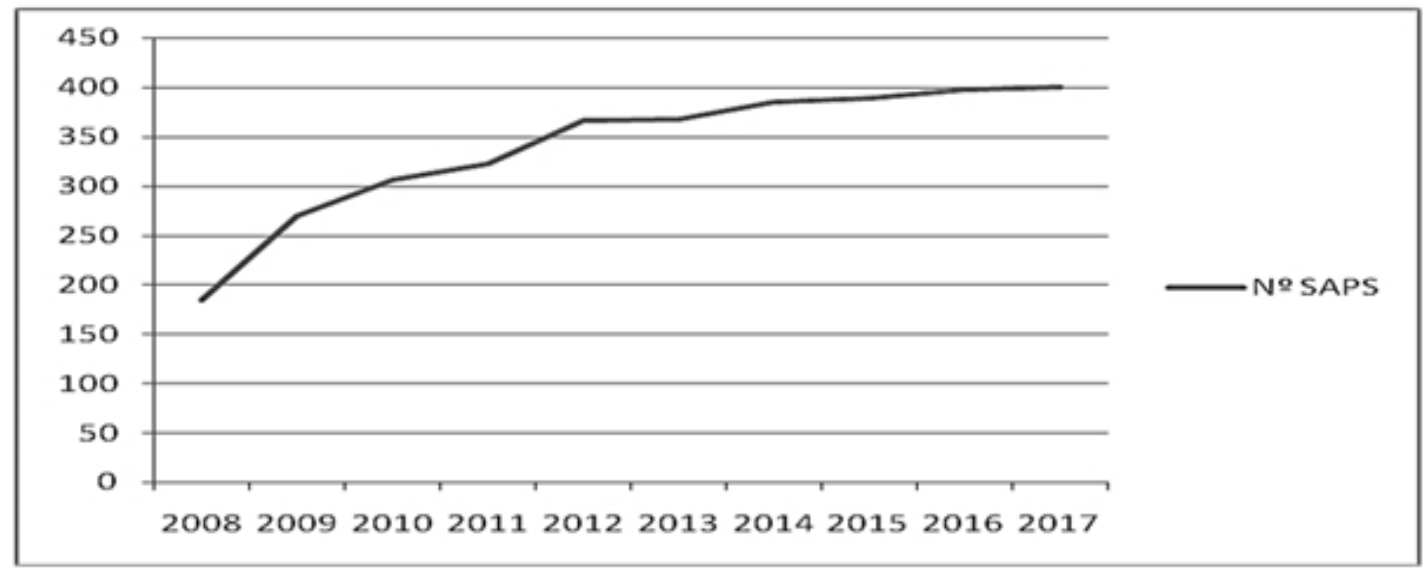

Fonte: Ministério da Saúde/DATASUS/Cadastro Nacional de Estabelecimentos de Saúde (CNES).

Figura 2 - Quantidade total de Centro de Atenção Psicossocial (CAPS), no município de São Paulo, no período de 2008 a 2017

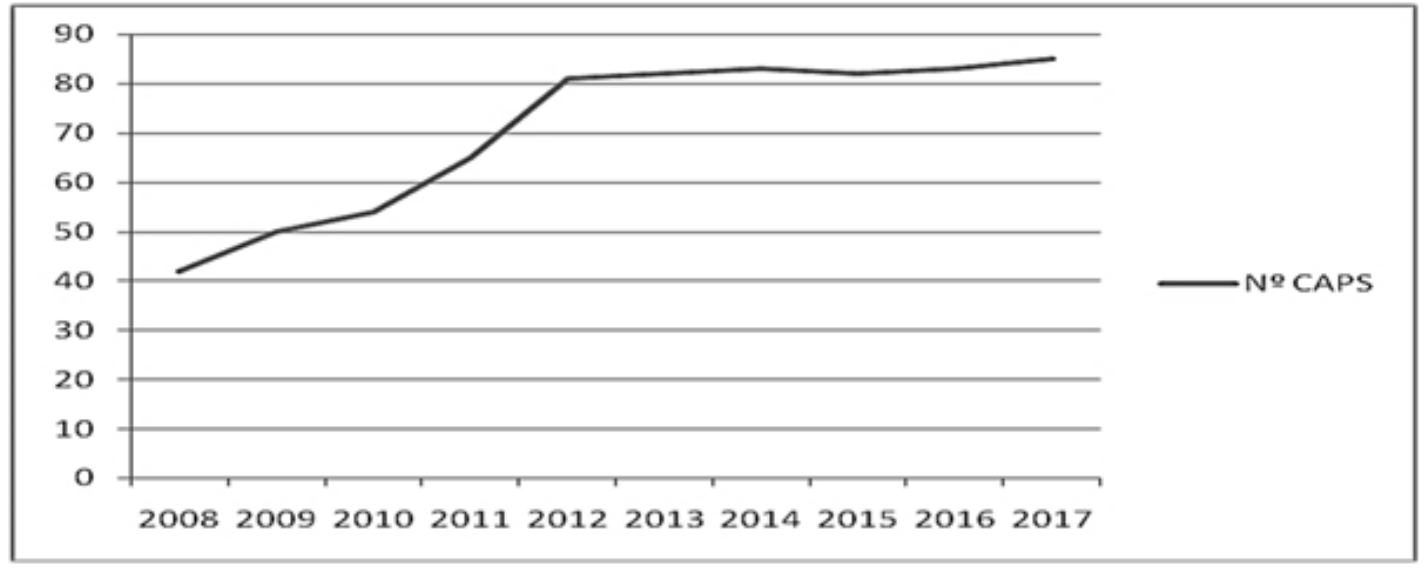

Fonte: Ministério da Saúde/DATASUS/Cadastro Nacional de Estabelecimentos de Saúde (CNES).

Já no quesito da regionalização dos serviços pelo município de São Paulo nas suas coordenadorias regionais de saúde, a Figura 3 revela de forma geral que as seis regiões (Centro, Norte, Leste, Oeste, Leste e Sudeste) apresentaram taxas de expansão similares, somente com um desvio para cima da região Sul e para baixo da região Oeste, apresentando uma correspondência com a Figura 1 em relação à taxa e período de maior intensidade. 
Figura 3 - Serviços de Atenção Psicossocial (SAPS) disponibilizados na Rede de Atenção Psicossocial (RAPS), no município de São Paulo, no período de 2008 a 2017

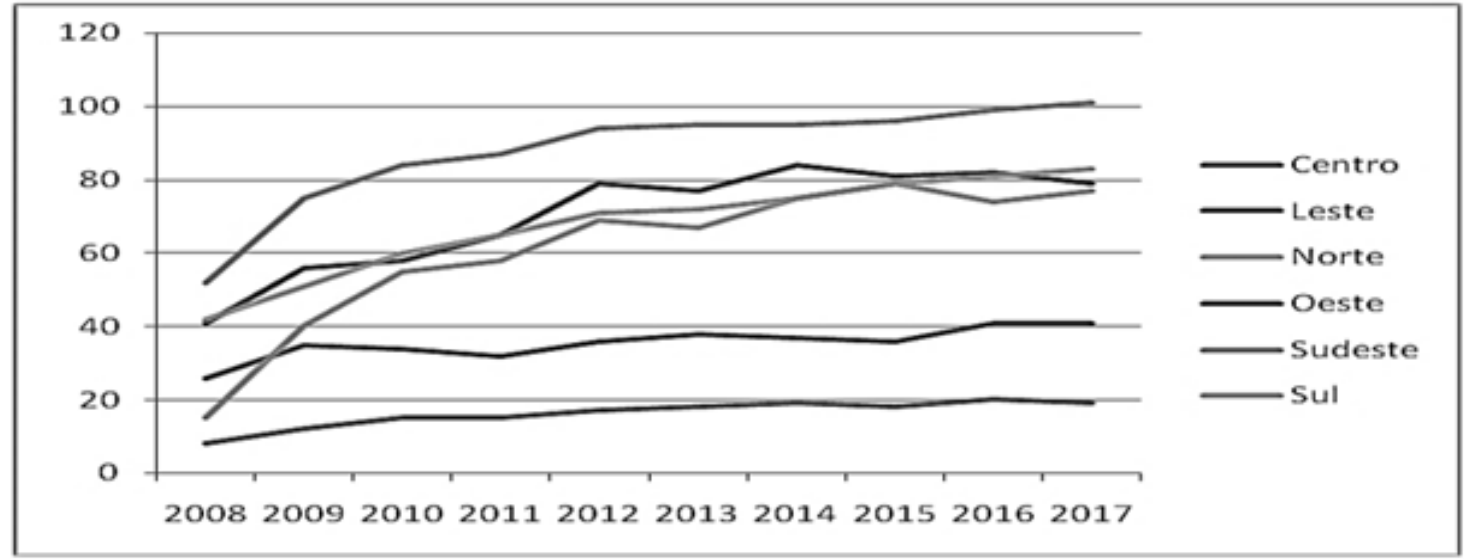

Fonte: Ministério da Saúde/DATASUS/Cadastro Nacional de Estabelecimentos de Saúde (CNES).

Entretanto, no processo de expansão dos CAPS é revelada uma discrepância com a tendência global dos serviços de saúde mental. A Figura 4 apresenta uma estagnação nas regiões Oeste e Centro e uma significativa expansão nas regiões Leste, Norte, Sul e Sudeste, porém, é nítida a certa diferença de intensidade na região de saúde Leste.

Figura 4 - Centro de Atenção Psicossocial (CAPS) estratificados por Coordenadorias de Regiões de Saúde (CRS), do município de São Paulo, durante o período de 2008 a 2017

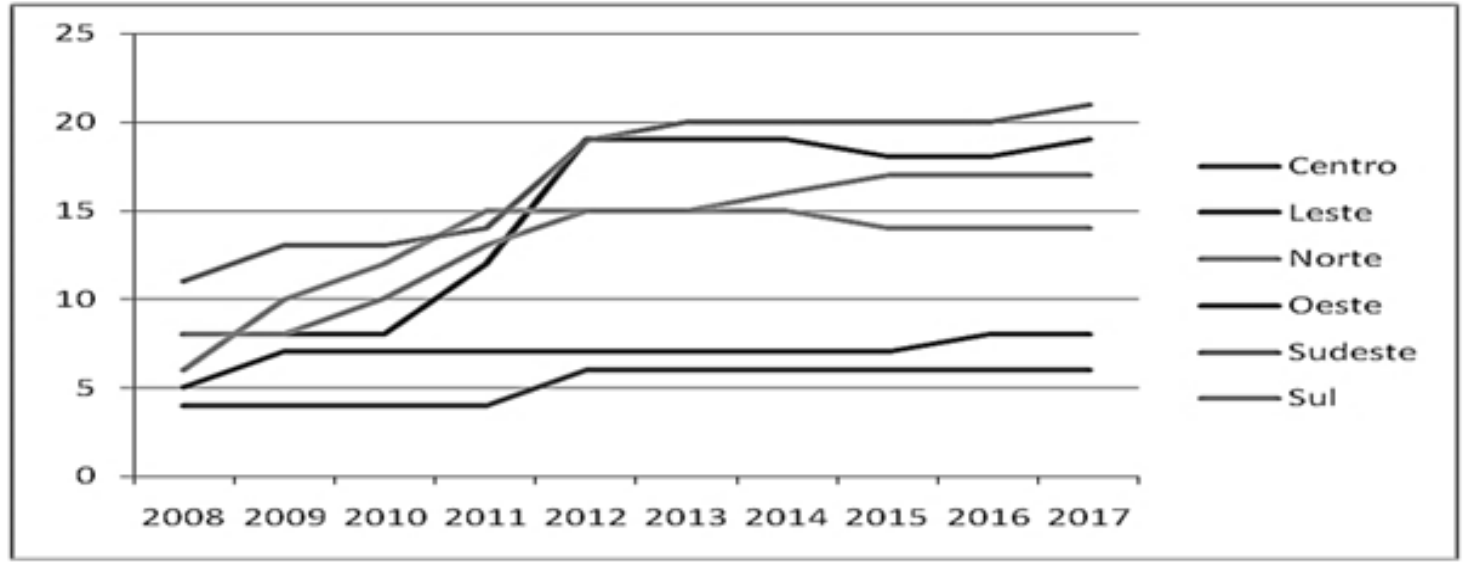

Fonte: Ministério da Saúde/DATASUS/Cadastro Nacional de Estabelecimentos de Saúde (CNES).

Focando a análise nos pontos associados a Leitos Psiquiátricos e à Autorização de Internação Hospitalar (AIH). Com relação aos leitos, a Figura 5 mostra uma tendência histórica de queda em sua quantidade absoluta, porém, sua distribuição entre as regiões e o processo de queda é desigual. Em primeiro lugar é notável a concentração nas regiões Norte e Sudeste e com certa manutenção das demais regiões, e em segundo, o processo histórico de queda real é concentrado em sua totalidade em apenas dois períodos que compreendem de 2007 a 2008 e de 2015 a 2016 e contraditoriamente entre estes períodos foi possível averiguar um aumento dos leitos. 
Figura 5 - Leitos de internação Psiquiátrica em sua composição total e estratificados em Coordenadorias Regionais de Saúde do município de São Paulo, no período de 2008 a 2017

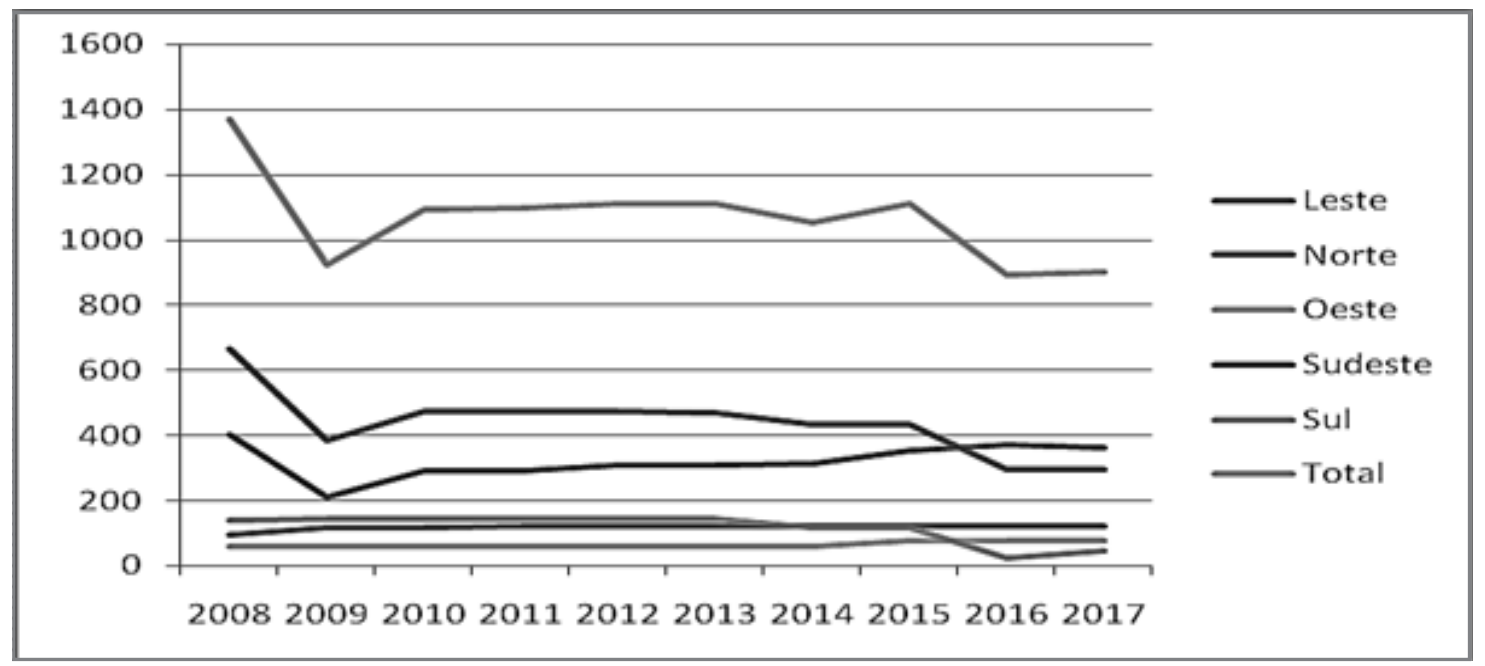

Fonte: Ministério da Saúde/DATASUS/Cadastro Nacional de Estabelecimentos de Saúde (CNES).

$\mathrm{Na}$ AIH, relacionada na Figura 6, é possível presenciar uma tendência a uma queda significativa nas internações hospitalares pelas causas psiquiátricas mais frequentes e uma manutenção do quadro epidemiológico, entretanto, os números absolutos ainda estão longe de serem diminutos.

Figura 6 - AIH (Autorização de internação Hospitalar) pagas estratificadas por CID-3 dígitos (Esquizofrenia, Psicose não orgânica e não esclarecida, Transtorno Afetivo Bipolar, Transtornos mentais devido ao uso de Álcool, Transtorno mentais devido ao uso de substâncias e Episódios Depressivos) no município de São Paulo, no período de 2008 a 2017

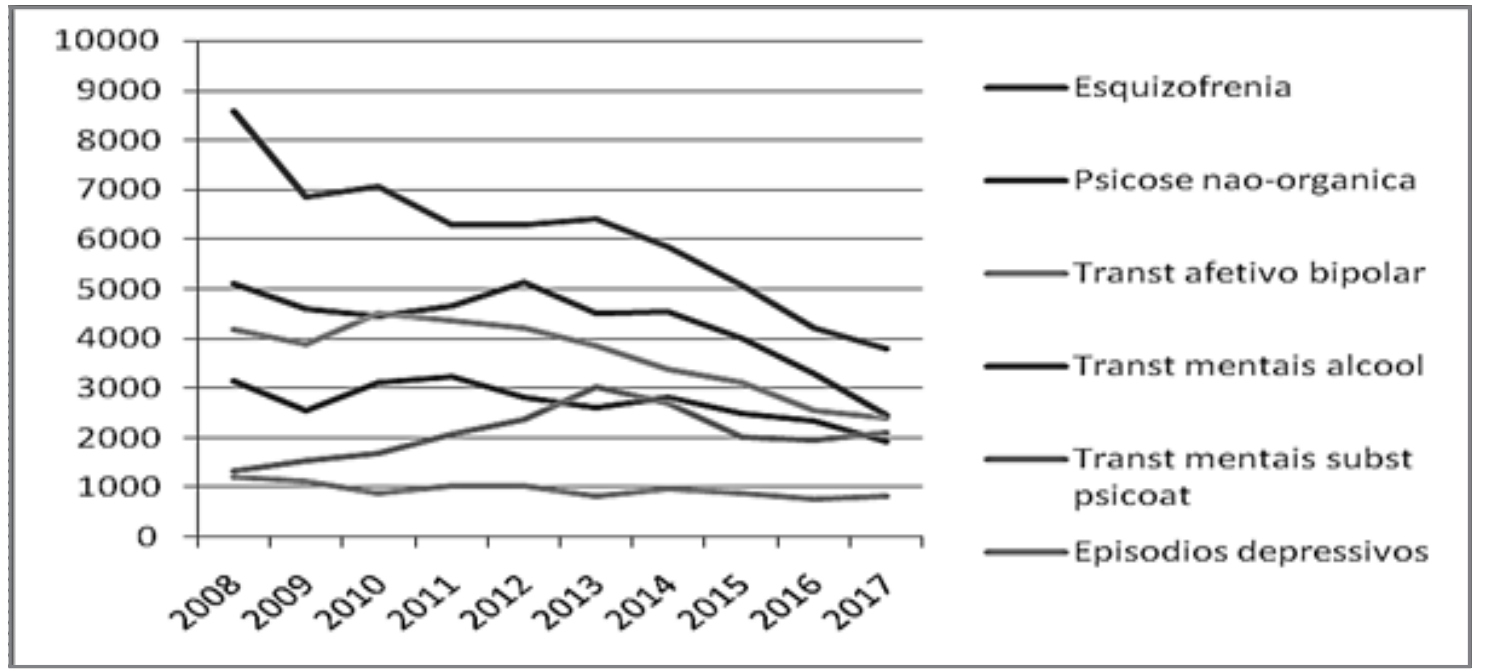

Fonte: Ministério da Saúde/DATASUS/Sistema de Informação Hospitalar (SIH).

Em relação aos atendimentos de profíssionais da área da saúde mental, a análise foi separada em dois blocos: o primeiro, especialistas médicos em Psiquiatria e o segundo profissionais com formação em Psicologia e Psicanálise. Esta divisão foi empregada justamente pelas diferenças importantes - outorgadas pela divisão técnica e social do trabalho - na finalidade, objetivos, instrumentos de trabalho utilizados por estes grupos de 
profissionais (MENDES-GONÇALVES, 1992), no qual a descentralização do trabalho na figura do médico representa gradual processo em direção à perspectiva psicossocial. No primeiro grupo analisado nas Figuras 7 e 8,- médicos psiquiatras - foi possível perceber uma tendência histórica de queda do número de atendimentos (de praticamente um terço no período estudado). Além disso, ocorreu uma acentuada concentração dessa categoria em serviços que permeiam a lógica hospitalar e com diminuição em CAPS e na Atenção Primária à saúde, podendo ser averiguado com nitidez entre os períodos de 2010 e 2015.

Figura 7 - Quantidade total de consultas com Médico especialista em Psiquiatria (C.PQ) nos serviços ofertados pela RAPS, no município de São Paulo, no período de 2008 a 2017

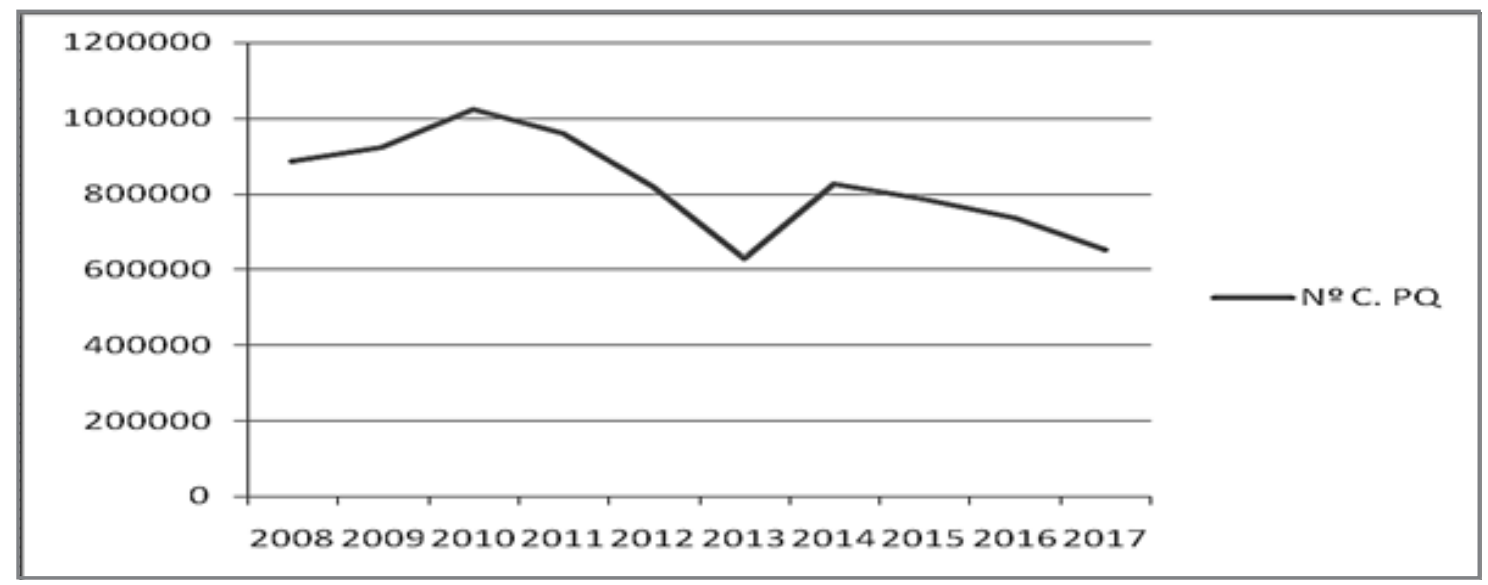

Fonte: Ministério da Saúde/DATASUS/Sistema de Informação Ambulatorial (SIA).

Figura 8 - Consultas com Médico especialista em Psiquiatria nos serviços de Centro de Atenção Psicossocial (CAPS), Unidade Básica de Saúde (UBS), Hospitais (HOSP), Pronto Socorro (PS), Centro de Atenção Integrado de Saúde Mental (CAISM) e Assistência Médica Ambulatorial (AMA), Ambulatório Médico de Especialidades (AME) e Ambulatórios em especificações (AMB) do município de São Paulo, no período de 2008 a 2017

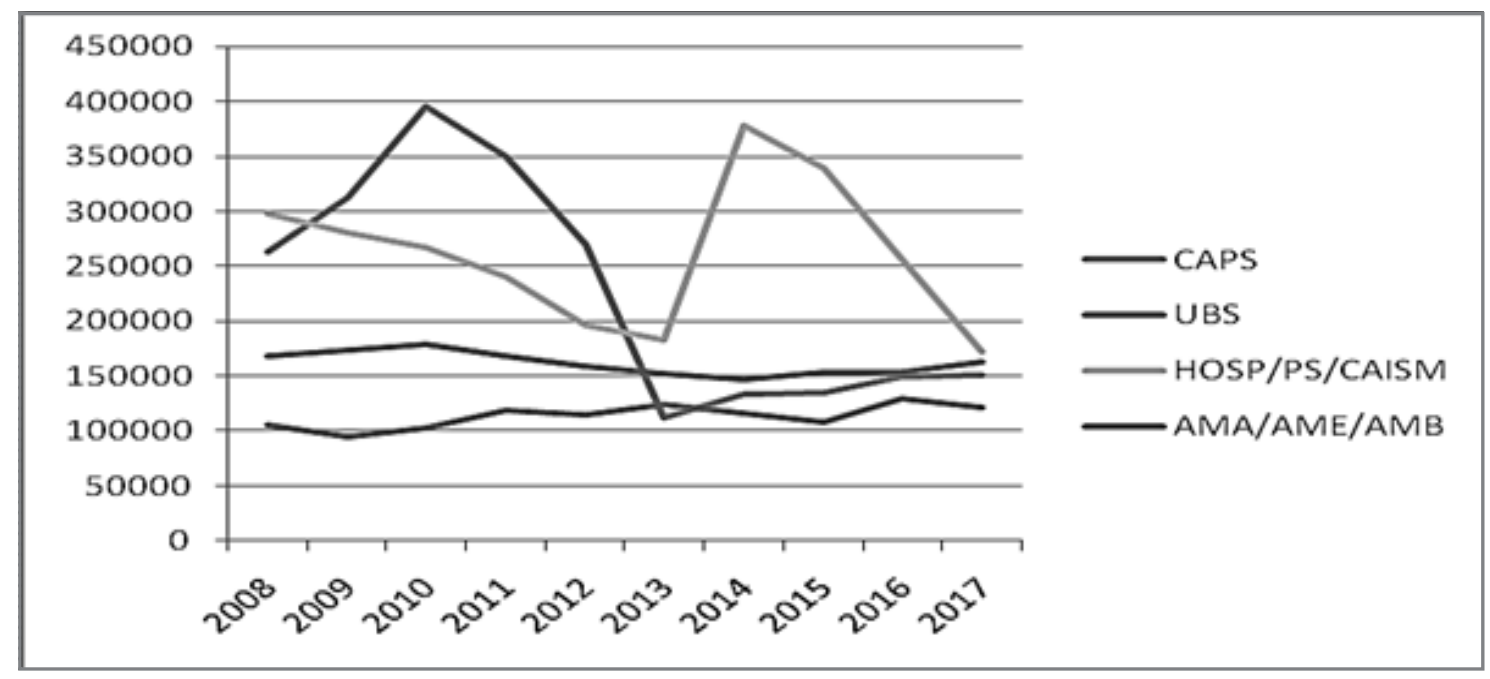

Fonte: Ministério da Saúde/DATASUS/Sistema de Informação Ambulatorial (SIA). 
Com relação ao segundo grupo - profissionais com formação em psicologia e psicanálise - podemos ver um movimento quase contrário nas Figuras 9 e 10, em que há uma tendência histórica de aumento gradual de atendimentos destes profissionais e praticamente em sua totalidade à custa de serviços de CAPS e CECCO apresentando uma estagnação na Atenção Primária (UBS).

Figura 9 - Quantidade total de consultas em Psicologia e Psicanálise (C. Psico) nos serviços ofertados pela RAPS, no município de São Paulo, no período de 2008 a 2017.

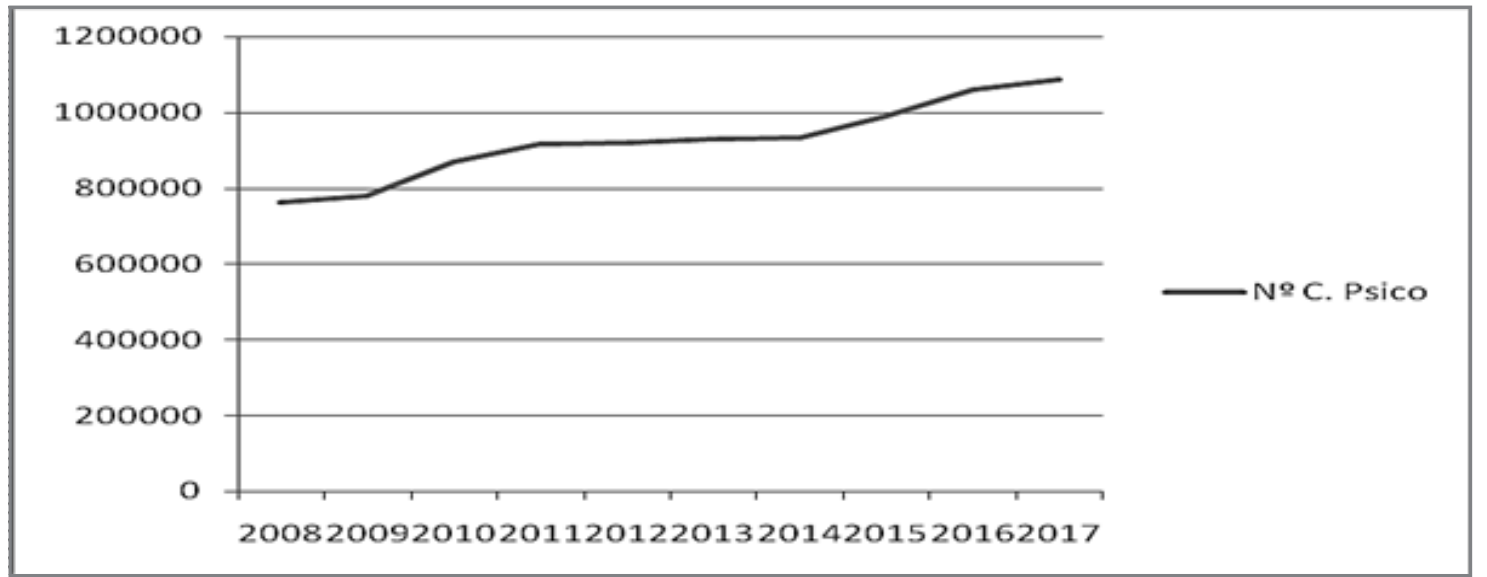

Fonte: Ministério da Saúde/DATASUS/Sistema de Informação Ambulatorial - SIA.

Figura 10 - Consultas em Psicologia e Psicanálise nos serviços de Centro de Atenção Psicossocial (CAPS), Centro de Convivência e Cooperativa (CECCO), Unidade Básica de Saúde (UBS), Hospitais, Centro de Atenção Integrada à Saúde Mental (HOSP/CAISM) e Assistência Médica Ambulatorial (AMA), Ambulatório Médico de Especialidades (AME) e Ambulatórios em especificações (AMB)

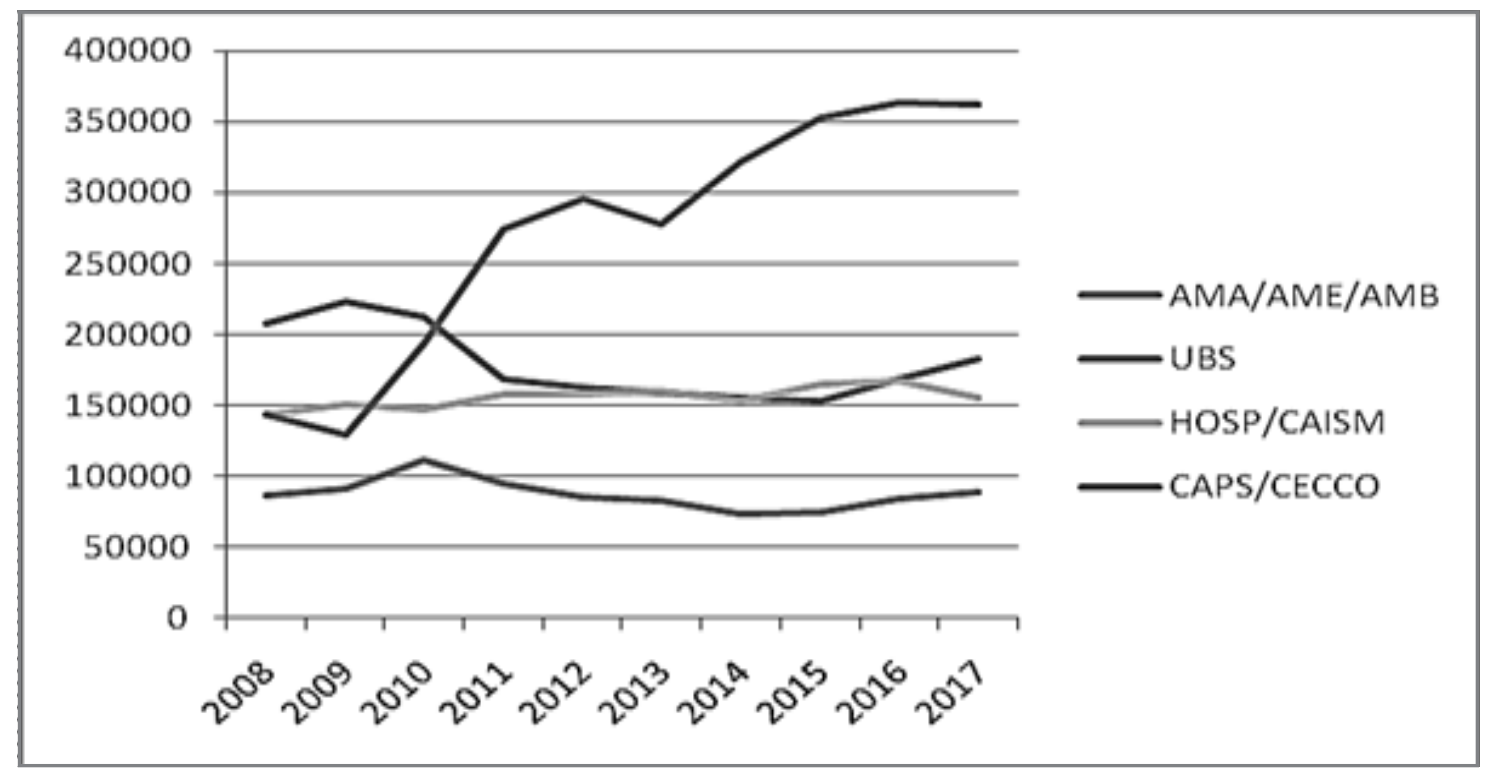

Fonte: Ministério da Saúde/DATASUS/Sistema de Informação Ambulatorial - SIA. 
O aspecto final desta análise histórica é a mortalidade por suicídio, expressa na Figura 11. Podemos reparar que existe uma variação absoluta mínima deste tipo especial de mortalidade, desse modo, não podemos inferir que o processo de expansão de serviços da Rede Atenção Psicossocial e seus diversos desdobramentos resultou em mudanças significativas neste padrão epidemiológico.

Figura 11 - Número bruto de suicídios no município de São Paulo, no período de 2008 a 2015

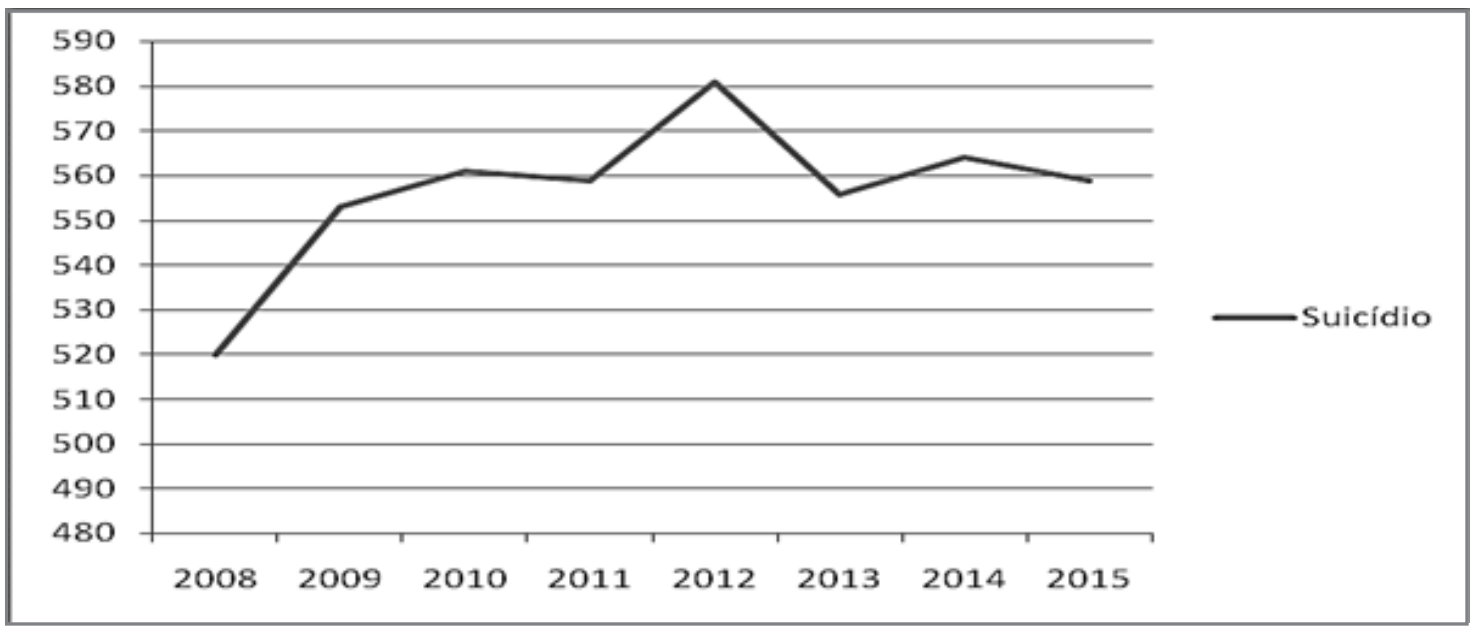

Fonte: Sistema de Informações sobre Mortalidade - SIM/PRO-AIM - CEInfo -SMS-SP.

O dado anteriormente descrito reforça a tese marxista de que os níveis de saúde de uma população segmentada em suas classes sociais - não podem ser simplesmente entendidos como uma questão de acesso ou disponibilidade de atenção à saúde. É sabido que a determinação social do processo saúde-doença está essencialmente ligada à reprodução das condições materiais do ser social (BREILH, 2006) podendo ser identificada neste padrão de mortalidade.

\section{Discussão}

A análise de tendência histórica da estruturação dos serviços de saúde mental sob a lógica da Reforma Psiquiátrica, no município de São Paulo, permite elaborar a hipótese de que seus avanços pragmáticos com relação ao acesso e atenção à saúde mental demonstram o moderno dentro do Sistema Único de Saúde (SUS). Como indicam os dados empíricos, apesar de engendrar avanços importantes na ampliação de serviços em níveis de atenção primária e secundária - em especial os CAPS - é possível dizer que o arcaico ainda persiste através da forte lógica de internações - leitos e AIHs.

Uma hipótese que pode ser levantada é que a permanência da assistência hospitalar pode estar associada ao grande capital que investe na organização de serviços na lógica procedimental e asilar (FONTES; FONTE, 2010). Isso sugere que a medicalização da loucura, especialmente em São Paulo, permanece lucrativa e permite considerável processo de acumulação para a fração burguesa que opera no setor de serviços (TEIXEIRA; PINTO, 2012) em países dependentes como o Brasil.

Nos últimos anos tem ocorrido a ampliação do acesso e disponibilidade de profissionais formados em uma perspectiva mais ampliada, orientada aos moldes psicossociais (BATISTA; GONÇALVES, 2011), porém, na área da saúde mental, estes tendem a se concentrar nos CAPS (PINHO; SOUZA; ESPIRIDIÃO, 2018) e apresentam dificuldades de integração com os serviços de Atenção Primária (UBS) (CARNUT, 2014). Ainda assim, a divisão técnica do trabalho coletivo intensifica-se pela concentração da força de trabalho de profissionais, especialmente os médicos especialistas, em serviços hospitalares e emergenciais. Isto pode estar dificultando, no polo do trabalho, a redução dos números totais dos atendimentos hospitalares à custa de sua substituição por modelos de atenção orientados aos CAPS.

Apesar de não tratarem diretamente do tema, Behring e Boschetti (2011) ajudam a compreender esta característica de incompletude da Reforma Psiquiátrica pelo avanço sistemático da hegemonia neoliberal. Este 
aspecto pode ser elucidado, em parte, devido à diminuição significativa do nível de organização das forças políticas presentes no período imediato do pós-1988, em particular o Movimento da Reforma Sanitária e Psiquiátrica. As subsequentes contrarreformas neoliberais, nesse período, desmobilizaram o poder de organização dos sanitaristas e da classe trabalhadora.

Além disso, essa hegemonia neoliberal traz consigo um 'receituário' para as políticas sociais ilustrado no trinômio 'privatização, focalização/seletividade e descentralização' (BEHRING; BOSCHETTI, 2011). Dessa maneira, somam-se às já árduas condições sociais impostas pela violência, miséria e superexploração da força de trabalho - intensificação da mais-valia relativa e absoluta, ordenada para a lógica do capital mundializado -, característica fundante de países de capitalismo dependente, conforme entendimento da Teoria Marxista da Dependência.

Por isso, a aparente ligação entre esses dados, pode em sua essência estar associado à posição em que o trabalho precarizado no setor de serviços (o arcaico), especialmente na imbricada mescla público-privado em que o SUS paulistano se conformou (PILOTTO; JUNQUEIRA, 2017), forçando diversos profissionais ao duplo vínculo. Esta característica do mundo do trabalho é, segundo Alves (2010), uma das posições específicas em que os proletários em condições de capitalismo dependente se apresentam.

Não é de estranhar que, a todo momento, este aspecto 'híbrido e incompleto' das reformas sociais retome a totalidade social e seja, portanto, um indicador concreto da dependência brasileira. De certo modo, o viés reformista das esquerdas de cunho socialdemocrata de uma maneira ou de outra esbarram nesta determinação, que, longe de estarem distante da realidade dos serviços expressam a tentativa de materialização de um Estado de 'bem-estar social' (como no caso dos serviços substitutivos de saúde mental) (o moderno).

A 'sobrevivência' da rede asilar/hospitalar (o arcaico) e que ainda acomoda parte significativa dos trabalhadores da área pode ser entendida como a insistência da fração burguesa que opera o setor de serviços em não desenvolver as forças produtivas internas (ou seja, a força de trabalho dos que adoecem psiquicamente) e tem pouquíssimo ou nulo compromisso com a questão social dos 'de baixo' (IANNI, 1992). Além disso, a acumulação de capital advindo da exploração - trabalho excedente - é remetida à divisão internacional do trabalho e, portanto, há pouca perspectiva de desenvolvimento nacional neste ambiente em que os termos de troca internacionais são constantemente deteriorados (MARINI, 2011) justificando, em certa medida, a permanência de modelos assistenciais liberais e centrados no modelo asilar/hospitalar.

A este cenário desfavorável é incorporado à inexorabilidade das crises cíclicas de superacumulação e superprodução do modo de produção capitalista - imanente

\section{Não é de estranhar que, a}

todo momento, este aspecto

'híbrido e incompleto' das

reformas sociais retome a

totalidade social e seja, portanto, um indicador

concreto da dependência

brasileira. à Lei do Valor. Ainda, pode-se dizer que esse processo é descortinado na lei da queda tendencial da taxa de lucro que expressa a tendência à diminuição da lucratividade do capitalista coletivo (MENDES, 2015; PAULO NETTO; BRAZ, 2012). Em resposta à esta tendência, o polo do capital operacionaliza contratendências, que no campo da política social, materializa-se pelas contrarreformas dos sistemas nacionais de seguridade social.

Na saúde mental, a contrarreforma deste subsetor remonta à volta ao passado (o arcaico), à persistência de modelos assistenciais de formato manicomial e que teve seu recrudescimento com a nomeação de Valencius Wurch, conhecido médico psiquiatra representante dos hospitais psiquiátricos para o cargo de coordenador nacional de saúde mental do Ministério da Saúde em 2017 (VIANA, 2017). Atualmente, esta investida neoliberal e o retorno à barbárie foram encarnados na figura do médico psiquiatra Quirino Cordeiro, responsável pela coordenação de Saúde Mental, Álcool e outras drogas do Ministério da Saúde entre 2017 e 2019 e, no momento, pela secretaria de Cuidados e Prevenção às drogas do Ministério da Cidadania. Na nota técnica de fevereiro de 2019 (BRASIL, 2019) atribui papel central do tratamento de dependentes de substâncias psicoativas às comunidades terapêuticas ${ }^{5}$, organizações sociais em discordâncias com os pressupostos da Reforma Psiquiátrica e marcadamente higienistas (BOLONHEIS-RAMOS; BOARINI, 2015; CONSELHO FEDERAL DE PSICOLOGIA, 2018), portanto, intensificando o desmonte da rede de atenção psicossocial e retorno da hegemonia do modelo manicomial.

Ademais, é pertinente pontuar que o Estado Social na Europa central foi uma experiência datada historicamente e não um conceito passível de replicação via reformas gradativas no sentido de aprimoramento das 
políticas públicas (BEHRING; BOSCHETTI, 2011). Em países dependentes como o Brasil é comum esperar que as frações da burguesia, na tentativa de reacomodarem o arcaico no moderno, exigem a justaposição anacrônica de soluções importadas de outras jurisdições para resolução da expressão interna de suas crises.

Aliada ao contexto do gasto público em saúde são particularmente nefastas as repercussões no sequestro do fundo público para pagamento dos juros dívida e o congelamento de gastos sociais, que, em termos de financiamento das ações de saúde mental tem sido o retrocesso vivido (BRASIL, 2017). Segundo o que se anuncia (MENDES; CARNUT, 2018), o sistema de saúde tende ao desfinanciamento à medida que o governo Bolsonaro não promova a revogação da Emenda Constitucional 95 que congela em 20 anos o gasto público em política social.

Em conjunto com as contribuições da análise crítica da política social e da economia política, é necessário se debruçar sobre a saúde enquanto objeto para melhor compreender a dificuldade em que os trabalhadores da rede substitutiva concebem, de maneira estrutural, a produção e reprodução da dialética saúde-doença. A partir do estudo da totalidade social - constituída pelo modo de produção e suas relações derivadas - a saúde é compreendida como categoria formada a partir de uma síntese de múltiplas determinações, ou seja, um processo de determinação social que subsumi a saúde aos condicionantes sociais de reprodução (BREILH, 2006). No entanto, os trabalhadores da saúde mental ainda permanecem na crença política da 'democratização dos serviços de saúde mental'. Por mais que esta democratização seja necessária, ela não é suficiente. Assim, na insistência de pensar que o SUS e demais políticas sociais não são determinadas pela inserção do Brasil no mercado mundial, há uma série de equívocos de análise que orientam a luta para mistificação institucional.

Além dessa característica 'mística', é necessário qualificar que tipo de saúde é produzida no âmbito dessa totalidade, permeada no subsetor da saúde mental pelas tensões das contradições imanentes das políticas sociais - legitimação e reprodução ampliada. Na perspectiva de Mendes-Gonçalves (1992), que trabalha a dialética da saúde-doença enquanto necessidade radical intrinsicamente ligada à ontologia do ser social - ou seja, o trabalho , é possível superar esta mistificação. Uma consequência de uma sociabilidade pautada pelas relações de produção capitalista, marcada por um verdadeiro giro antropológico (MÁRKUS, 2015) entre o gênero humano e a mercadoria, verifica-se a impossibilidade de realização da saúde enquanto necessidade humana radical, ou seja, derivada da desalienação do trabalho e da desfetichização de mercadoria (MARX, 2017).

Isto pode ser aproximado ao descompasso da política social de saúde mental, que mesmo incialmente baseada na legitimação - luta por direitos sociais e desmantelamento de manicômios - encontra sérios entraves para satisfazer as necessidades radicais de saúde da ampla maioria da população, justamente por estas serem reorientadas para a reprodução ampliada do processo de acumulação capitalista nas especificidades da dependência.

Em suma, a dinâmica da dependência determinada pela inserção na economia mundial e pela transferência de mais-valia advinda da superexploração (MARINI, 2011), impõe uma lógica particular sobre o desenvolvimento das reformas e seus decorrentes modelos de assistência à saúde. Essa particularidade é materializada pela dialética entre o moderno e o arcaico. Dessa maneira, não é possível interpretar essa complexa relação como uma mera coexistência antagônica, em que o avanço do moderno no cotidiano dos serviços e instituições pode levar ao declínio do arcaico. Pelo contrário, essa 'mescla' é parte constitutiva e é derivada da formação social e do processo de acumulação capitalista, ou seja, enquanto a totalidade social for determinada pela dependência esta dialética tende a ser preservada.

Portanto, a estratégia do movimento da Reforma Psiquiátrica, marcada pela via institucional, encontra na dependência brasileira um entrave estrutural para realização da saúde mental enquanto necessidade da emancipação humana. Desse modo, progressivamente se institucionalizando e se deslocando do conjunto das lutas da classe trabalhadora, o que pode implicar na fragilidade perante os avanços das contrarreformas neoliberais e na crescente volta da hegemonia do arcaico.

A partir destas chaves de interpretação - crítica da política social e da economia política e análise da saúde em suas particularidades como categoria social - é reforçada a hipótese inicial de que a Reforma Psiquiátrica desenvolveu-se incompletamente conjugando elementos do arcaico e do moderno. Mesmo nos parcos avanços, durante o período entre 2002 e 2016 de hegemonia política do Partido dos Trabalhadores (PT) marcada pela tentativa reeditada do projeto desenvolvimentista e conciliação de classes, não houve, como os dados demonstram, a superação dos modelos.

\section{Considerações finais}

Este estudo apresentou uma primeira aproximação com a problemática das reformas na saúde mental, pela perspectiva da teoria marxista da dependência. 
Mesmo trabalhando com dados de séries históricas de um período de dez anos, é pertinente atentar que os dados apresentam limites ao validar as hipóteses da interpretação encetada por este estudo. Dentro de uma perspectiva materialista e histórica conhecemos que a Reforma Psiquiátrica traz avanços substanciais, porém, possui características incompletas e hibridiza com diferentes perspectivas de atenção à saúde. Isto, do ponto de vista da TMD pode ser compreendida como uma mescla entre o arcaico o moderno que caracteriza a contradição da dependência.

Em termos empíricos, pode-se dizer que o focalizar dentro do próprio setor saúde por não privilegiar a Atenção Primária como lócus fundamental enclausurando-se em níveis secundários, a saúde mental não transformou estruturalmente o perfil de morbimortalidade e na prática não rompeu radicalmente com o modelo asilar.

Em suma, dentro de uma perspectiva fundamentada no método materialista histórico-dialético e nas particularidades da díade arcaico-moderno da formação social brasileira, a Reforma Psiquiátrica brasileira dificilmente romperá estes entraves impostos caso não retome uma perspectiva radical de saúde que enfrente a alienação e o fetiche do 'Estado protetor' apresentando uma alternativa anticapitalista e emancipatória.

Ademais, são necessários novos estudos filiados à teoria marxista da dependência e na expansão da magnitude e diversidade dos dados empíricos coletados para mais precisamente fundamentar as hipóteses apresentadas.

\section{Referências}

ALVES, G. Trabalho, subjetividade e capitalismo manipulatório: o novo metabolismo social do trabalho e a precarização do homem que trabalha. 2010. Disponível em: http://www.giovannialves.org/artigo_giovanni\%20alves_2010.pdf. Acesso em: 20 jun. 2019.

AMARANTE, P.; TORRE, E. H. G. 30 anos da Reforma Psiquiátrica Brasileira: lutando por cidadania e democracia na transformação das políticas públicas e da sociedade brasileira. In: FONTES, B.; FONTE, E. M. M. Desinstitucionalização, redes sociais e saúde mental: análise de experiências da reforma psiquiátrica em Angola, Brasil e Portugal. Recife: Ed. Universitária da UFPE, p. 113135, 2010.

BALLARIN, M. L. G. S.; MIRANDA, I. M. S.; FUENTES, A. C. R. C. Centro de atenção psicossocial: panorama das publicações de 1997 a 2008. Psicologia, Ciência e Profissão, Brasília, v. 30, n. 4, p. 726-737, dez. 2010.

BALLARIN, M. L. G. S. et al. Centro de atenção psicossocial: convergência entre saúde mental e coletiva. Psicologia em Estudo, Maringá, v. 16, n. 4, p. 603-611, dez. 2011.

BATISTA, K. B. C.; GONÇALVES, O. S. J. Formação dos Profissionais de Saúde para o SUS: significado e cuidado. Saúde e Sociedade, São Paulo, v. 20, n. 4, p. 884-899, out./dez. 2011.

BEHRING, E. R.; BOSCHETTI, I. Política social: fundamentos e história. 9. ed. São Paulo: Cortez, 2011.

BOLONHEIS-RAMOS, R. C. M.; BOARINI, M. L. Comunidades terapêuticas: "novas" perspectivas e propostas higienistas. História, Ciências, Saúde - Manguinhos, Rio de Janeiro, v. 22, n. 4, p. 1231-1248, out./dez. 2015.

BOSCHETTI, I. Assistência social e trabalho no capitalismo. São Paulo: Cortez, 2016.

BRASIL. Lei $n^{\circ}$ 10.216, de 6 de abril de 2001. Disponível em: http://www.planalto.gov.br/ccivil_03/leis/LEIS_2001/L10216.htm. Acesso em: 20 jun. 2019.

BRASIL. Nota Técnica $n^{\circ}$ 11/2019-CGMAD/DAPES/SAS/MS, de 4 fevereiro de 2019. Esclarecimentos sobre as mudanças na Política Nacional de Saúde Mental e nas Diretrizes da Política Nacional sobre drogas. Disponível em: https://www.abrasco.org.br/site/wpcontent/uploads/2019/02/11_23_14_123_Nota_Te\%CC\%81 cnica_no.11_2019_Esclarecimentos_sobre_as_mudanc\%CC\%A7as_da_ Politica_de_Sau\%CC\%81de_Mental.pdf. Acesso em: 20 jun. 2019.

BRASIL. Portaria $n^{\circ} 3.58 \overline{8}$, de 21 de dezembro de 2017. Disponível em: http://bvsms.saude.gov.br/bvs/saudelegis/gm/2017/ prt3588_22_12_2017.html. Acesso em: 20 jun. 2019.

BREILH, J. Epidemiologia critica: ciência emancipadora e interculturalidade. Rio de Janeiro: Editora Fiocruz, 2006.

CARNUT, L. Entre o modelo biomédico e o psicossocial: uma análise das propostas terapêuticas dos profissionais de saúde de um centro de atenção psicossocial para álcool e outras drogas (CAPSad) na cidade do Recife. 2014. Trabalho de Conclusão de Curso (Graduação em Ciências Sociais-Licenciatura) - Universidade Federal de Pernambuco (UFPE), Pernambuco, 2014.

CONSELHO FEDERAL DE PSICOLOGIA (CFP). Relatório da inspeção nacional em comunidades terapêuticas - 2017. Brasília: Conselho Federal de Psicologia, 2018.

COSTA, N.R. et al. Reforma psiquiátrica, federalismo e descentralização da saúde pública no Brasil. Ciência \& Saúde Coletiva, Rio de Janeiro, v. 16, n. 12, p. 4603-4614, dez. 2011.

DANTAS, A. V. Do socialismo à democracia: tática estratégia na reforma sanitária brasileira. Rio de Janeiro: Ed. Fiocruz, 2017.

FERNANDES, F. Capitalismo dependente na América Latina. 4. ed. São Paulo: Globo, 2009.

FLEURY, S. Reforma sanitária: em busca de uma teoria. São Paulo: Cortez, 1989.

FONTES, B.; FONTE, E. M. M. (org.). Desinstitucionalização, Redes Sociais e Saúde Mental: Análise de Experiências da Reforma Psiquiátrica em Angola, Brasil e Portugal. Recife: Editora Universitária da UFPE, 2010. 
IANNI, O. A ideia de Brasil moderno. São Paulo: Brasiliense, 1992.

JACOBINA, A. O. A relação do Cebes com o PCB na emergência do movimento sanitário. Saúde em Debate, Rio de Janeiro, v. 40, n. spe, p. 148-162, dez. 2016. ISSN 2358-2898. DOI http://dx.doi.org/10.1590/0103-11042016s13.

LUCE, M. S. Teoria Marxista da Dependência: problemas e categorias: uma visão história. São Paulo: Expressão Popular, 2018.

MARINI, R. M. Dialética da dependência. In: STEDILE, J. P.; TRASPADINI, R. (org.). Ruy Mauro Marini: vida e obra. São Paulo: Expressão Popular, 2011. p. 131-172.

MÁRKUS, G. Marxismo e antropologia: o conceito de 'essência humana' na filosofia de Marx. São Paulo: Expressão Popular, 2015. MARX, K. O capital: crítica da economia política: livro 1: o processo de produção do capital. 2. ed. São Paulo: Boitempo, 2017.

MENDES, A. Brazilian public health in the context of a State crisis or a crisis of capitalism? Saúde e Sociedade, São Paulo, v. 24 , supl. 1, p. 66-81, jun. 2015

MENDES, A.; CARNUT, L. Capitalismo contemporâneo em crise e sua forma política: o subfinanciamento e o gerencialismo na saúde pública brasileira. Saúde e Sociedade, São Paulo, v. 27, n. 4, p. 1105-1119, out. 2018.

MENDES-GONÇALVES, R. B. Práticas de saúde: processos de trabalho e necessidades. São Paulo: Secretaria Municipal de Saúde, 1992.

OLIVEIRA, F. Crítica à razão dualista: o ornitorrinco. São Paulo: Boitempo, 2013.

PAIM, J. S. Reforma sanitária brasileira: contribuição para a compreensão e crítica. Salvador: EDUFBA; Rio de Janeiro: FIOCRUZ, 2008.

PAULO NETTO, J. P.; BRAZ, M. Economia política: uma introdução crítica. 8. ed. São Paulo: Cortez, 2012.

PILOTTO, B. S.; JUNQUEIRA, V. Organizações Sociais do setor de saúde no estado de São Paulo: avanços e limites do controle externo. Serviço Social e Sociedade, São Paulo, n. 130, p. 547-563, set./dez. 2017.

PINHO, E. S.; SOUZA, A. C. S.; ESPERIDIÃO, E. Processos de trabalho dos profissionais dos Centros de Atenção Psicossocial: revisão integrativa. Ciência \& Saúde Coletiva, Rio de Janeiro, v. 23, n. 1, p. 141-152, jan. 2018.

TEIXEIRA, R. A.; PINTO, E. C. A economia política dos governos FHC, Lula e Dilma: dominância financeira, bloco no poder e desenvolvimento econômico. Economia e Sociedade, Campinas, v. 21, n. spe, p. 909-941, dez. 2012.

TOMAZ, C. S. A cidadania do louco: um debate necessário para a compreensão da direção teórico-política da Luta Antimanicomial. 2009. 201 f. Dissertação (Mestrado em Serviço Social) - Universidade Federal de Juiz de Fora, Juiz de Fora, MG, 2009.

VIANA, B. B. Desculpem o transtorno (mental), estamos em reforma (psiquiátrica): a luta antimanicomial brasileira e o movimento Fora Valencius. 2017, 61f. Monografia (Residência Multiprofissional em Saúde Mental) “Faculdade de Ciências Médicas, Universidade de Pernambuco, Pernambuco, 2017.

\section{Notas}

1 Aqui reconhecemos o termo 'reforma' em seu sentido original cunhado pela esquerda socialdemocrata, especialmente quando nos referimos ao debate entre Lênin-Kautsky e Rosa-Bernstein. Em termos históricos, a esquerda democrática que constitui o campo da Saúde Coletiva (e, em certa medida, da Saúde Mental) é caudatária da opção socialdemocrata, muito influenciado pelo Partido Comunista Italiano, cujo um dos seus líderes foi Enrico Berlinguer. Seu irmão, Giovanni Berlinguer, teve influência decisiva na Reforma Sanitária e Psiquiátrica Italiana. Para maiores detalhes, ver Dantas (2017).

2 A teoria marxista da dependência (TMD) constitui uma das vertentes mais importantes do pensamento crítico no continente. Concebida no bojo da luta de classes na América Latina dos anos 1960/1970, principalmente por pensadores brasileiros como Rui Mauro Marini, Theotônio dos Santos e Vania Bambirra, sintetiza o encontro entre a teoria do valor de Marx e a teoria marxista do imperialismo formulada por Lenin. Desse encontro foram criadas categorias originais, como: superexploração da força de trabalho, transferência de valor, subimperialismo, padrão de reprodução do capital e a própria categoria dependência dos países latino-americanos. Todas elas contribuem para explicar os processos e tendências específicas da América Latina no âmbito da totalidade integrada do capitalismo mundial. Para um aprofundamento da TMD, ver Luce (2018).

3 Consideramos que no Brasil nunca existiu, de fato, um Estado de Bem-Estar Social aos moldes europeus. Mesmo quando consideramos a Europa ocidental e seus sistemas de proteção, preferimos a análise de Boschetti (2016) que considera esta construção categorial problemática demonstrando as evidências de que se trata de um 'Estado Social Capitalista', no qual as políticas sociais foram fundamentais para reaquecer o padrão de acumulação capitalista nos países centrais atuando como um dos elementos de contratendência à lei tendencial da queda da taxa de lucro.

4 Os movimentos sociais da saúde mental apresentaram momentos de saltos organizativos, como na VIII Conferência Nacional em Saúde (1986), a I e II Conferência Nacional em Saúde Mental (1987; 1992), o II Congresso Nacional de Trabalhadores em Saúde Mental (1987) e a Declaração de Caracas em 1990 (AMARANTE; TORRE, 2010). Este processo engendrou no Movimento de Trabalhadores de Saúde Mental uma crítica radical ao modelo asilar/hospitalar, ou seja, era necessário o total rompimento. Em 1987 o Movimento dos Trabalhadores em Saúde Mental (MTSM) se transforma no Movimento da Luta Antimanicomial (MLA) que, por sua vez, criticava a limitação da luta pela via institucional e por dentro do Estado, vieses marcadamente presentes no movimento sanitarista. Após uma cisão no movimento social, a Rede Nacional Internúcleos da Luta Antimanicomial (RENILA) e o Movimento Nacional da Luta Antimanicomial (MNLA) formam o quadro atual de movimentos sociais (TOMAZ, 2009). 
5 As comunidades terapêuticas, além de negarem os pressupostos da RPB, apresentam denúncias de práticas abusivas e, em certos casos, até mesmo proscritas como a 'laborterapia' (a noção de trabalho como terapêutico e moralizante remonta ao século XVIII). Esta prática, na realidade, funciona como exploração da força de trabalho dos pacientes, que forçadamente realizam serviços dentro e fora dos desígnios da comunidade, geralmente em condições degradantes. Outra realidade bárbara é o emprego de tortura sob a forma de privação de sono, supressão de alimentação, isolamento por longos períodos e contenções químicas e mecânicas fora de seu uso estrito. Para maiores detalhes, ver Conselho Federal de Psicologia (2018).

\section{Daniel Figueiredo de Almeida Alves}

d.fig94@gmail.com

Graduado em Medicina pela Faculdade de Ciências Médicas da Santa Casa de São Paulo

Médico Generalista (FCMSCSP)

\section{FCMSCSP}

Rua Dr. Cesário Motta Júnior, $n^{\circ} 61$ - Vila Buarque

São Paulo - SP - Brasil

CEP: 01221-020

\section{Áquilas Mendes}

aquilasmendes@gmail.com

Doutor em Ciências Econômicas pela Universidade de Campinas

Professor Livre-Docente pela Faculdade de Saúde Pública da Universidade de São Paulo (FSP-USP)

\section{FSP-USP}

Rua Dr. Arnaldo, $\mathrm{n}^{\circ} 715$ - Cerqueira César

São Paulo - SP - Brasil

CEP: 01246-904

\section{Leonardo Carnut}

leonardo.carnut@gmail.com

Doutor em Saúde Pública pela Faculdade de Saúde Pública da Universidade de São Paulo

Professor Adjunto do Centro de Desenvolvimento do Ensino Superior em Saúde da Universidade Federal de São Paulo (UNIFESP)

\section{UNIFESP}

Rua Pedro Toledo, 603 - Vila Clementino

São Paulo - SP - Brasil

CEP: 04039-032

\section{Oziris Simões}

ozirissimoes2@gmail.com

Doutor em Ciências da Saúde pela Faculdade de Ciências Médicas da Santa Casa de São Paulo

Professor Assistente no Departamento de Saúde Coletiva da Faculdade de Ciências Médicas da Santa Casa de São Paulo (FCMSCSP)

\section{FCMSCSP}

Rua Dr. Cesário Motta Júnior, $n^{\circ} 61$ - Vila Buarque

São Paulo - SP - Brasil

CEP: 01221-020 
Agência financiadora

Não se aplica.

\section{Contribuições dos autores}

Daniel Figueiredo de Almeida Alves, Oziris Simões, Leonardo Carnut e Áquilas Mendes contribuíram igualmente na elaboração do manuscrito.

Aprovação por Comitê de Ética e consentimento para participação

Não se aplica.

\section{Consentimento para publicação}

Não se aplica.

\section{Conflito de interesses}

Não há conflito de interesses. 